\title{
PULSE, A Waveform Model for River Isotopic and chemical Time-series Data
}

\author{
Mohamed Fahmy Hussein ${ }^{1}$, Kamal Zouari ${ }^{2}$, Mohamed Anter ${ }^{3}$, and Mariam Nosser ${ }^{4}$ \\ ${ }^{1}$ profdrfahmy@cu.edu.eg, ${ }^{2}$ kamel.zouari@enis.tn, ${ }^{3}$ mohamed anter@nwrc.gov.eg, \\ ${ }^{4}$ mariamnosser93@gmail.com \\ ${ }^{1}$ https://orcid.org/0000-0003-0891-212X \\ ${ }^{1}$ Corresponding author \\ ${ }^{1,4}$ Cairo University, Egypt, ${ }^{2}$ École Nationale d'Ingénieurs de Sfax, ENIS, Tunisie, \\ ${ }^{3}$ National Water Research Center, Egypt.
}

\begin{abstract}
The isotopic composition and electrical conductivity frequently change with time in river water worldwide, on various time scales. Periodicity is also known for precipitation and other aqueous inputs. The time-series follow up of such variations is usually to proceed by many hydrologists. The major purpose is to gain a thorough understanding of the underlying phenomena and to plot the data accurately. However, there is no appropriate formula for the graphic illustration and mathematical expression of such fluctuations other than the complicated Fourier Series. Also, the use of the trigonometric sin function is not possible due to constraining the values between +1 and -1 . In contrast, the isotopic compositions require negative and positive values on the $y$-axis corresponding to time on the -x-axis, while the hydrochemical concentrations only admit positive values. These constraints are entirely void in the flexible waveform PULSE model proposed in this work. In this model, we introduce a modified sinusoidal formula that has the exciting capability of freely controlling the graphic waveform, in a highly accommodating way, for plotting the time-series isotopic and hydrochemical pulses in conformity with field observations. Three main parameters, and two optional secondary parameters, are to use in our function, open to modification. The model is to use in Excel ${ }^{\circledR}$, whose SOLVER built-in macro may give the approximate values for the main parameters. Such values are then to improve to get the waveform best visual fit manually. We applied PULSE on $\mathrm{EC}, \mathrm{Cl}$, and $\delta^{18} \mathrm{O}$ values for Nile water, Cairo, and progressively improved the parameters' values as new data was to obtain. The sexagesimal angles are to handle for plotting the sampling dates on the $\mathrm{x}$-axis. The angle that corresponds to one day $=360^{\circ} / 356.24$ days year ${ }^{-1}=0.9856^{\circ}$ day $^{-1}=$ $0.0172 \mathrm{rad} \mathrm{day}^{-1}$. The regular Excel ${ }^{\circledR}$ time and date-functions are also to use to assign the time-series sampling dates. The two optional parameters, $\beta$ and $\gamma$, are to use only to damp or expand a decayed or stretched future pulses; otherwise, the values of those secondary parameters should be zero. The parent of the fundamental PULSE formula is a flickering medical equation (Sinusoidal Amplitude-modulated Flicker Function) used in the optical-fitness experiments run for testing the human vision adaptation to light luminance, using the appropriate electrophysiological devices. PULSE stands alone in its hydrological category. This model offers a unique quantitative definition for the isotopic and hydrochemical pulses in successive waveforms, with adjustable values for its parameters, in response to the involved variable and the sampling dates. Measurements on Nile water, using daily river water sampling for several years, were to carry out. PULSE revealed its practical merits for an extensive Nile water data set. Such data are for $\delta^{18} \mathrm{O} / \mathrm{V}-\mathrm{SMOW} \%$, EC dS/m, and $\mathrm{Cl} \mathrm{mg} / \mathrm{l}$, PULSE works fine for such a riverine system. This application included a rare event of exceptional runoff suddenly imposed on Cairo Nile water composition by a scarce flash thunderstorm, where unusual waveforms were to assign to the isotopic and chemical trails of such abnormal runoff in the Sahara. Such a rare event was to use to get a backward look to the paleo-hydrology of the River Nile water composition in Egypt.
\end{abstract}

KEYWORDS Isotope Hydrology; Waveform; Sinusoidal function; River Water EC Oscillation. 


\section{Introduction}

The research worker in hydrology usually obtains qualitative and quantitative observations in space and time. Such variables are to measure in the field and laboratory. Finding a suitable way of data-presentation occupies a vital role in the interpretation of the recorded observations in both the community-reports and scientific publications. The quantitative treatment of the riverine hydrological system makes data much more representative of the concerned phenomena, hidden under the mass of evidence, than the qualitative methods. The time-series record of the hydrochemical and isotopic variables in river hydrology deals with data-collection, at a specific location, and data analysis and graphical visualization within the selected laps of time, to get a valid interpretation of the involved phenomena. The long-term record of dynamic changes in river water chemistry and isotopic composition could be challenging since this effort needs enough resources and personnel. However, the hard part of the time-series study is to render the collected observations readable and their interpretation meaningful albeit the presence of multiple contributions to water-composition change within river trunk with time (runoff, baseflow, urban zone impact, human intervention in the river system to store water in artificial lakes in front of dams to combat high and low floods, and other inputs). The long-term record of the studied hydrochemical river-water variables may show ups and downs in a quasi-regular pattern along the hydrologic year. It is crucial to find an appropriate mathematical formula that can illustrate such temporal variations that may include rare anomalous events.

This work presents a new waveform to express the temporal changes in river water chemical composition, namely the solute load, and the isotopic ratio (e.g., $\left.\delta^{18} \mathrm{O}\right)$. The approach for finding a flexible waveform formula may give trails to certain trigonometric or polynomial functions; however, the shouting-out of the plausible range and the impossible usage of negative values in some of these functions blocks its applicability in river hydrology. The suitable waveform function must have a small number of parameters and should be open to the introduction of more parameters by the user as needed in specific cases of application to change the oscillation-pace, amplitude, and peak-slope trend. The most important feature of the required wave function is to flexibly accept negative and positive values for the y-axis variable with no restriction in its mathematical formula. A case study application for the Nile water solute concentration and the river water isotopic composition is to discover in this work using the introduced PULSE function.

\section{Materials and Methods}

River Nile water samples were to collect daily, by mid-day, at the middle of the Nile course, between Cairo University bridge and Abbas bridge at Giza, Cairo, Egypt, starting late October 2016 and up to the present day. Sampling will be further going for one extra year span. Each water sample was to collect in two fractions; one fraction is a half-liter ordinary clean plastic bottle and a $13.8 \mathrm{ml}$ fraction in a small glass vial, both filled to the top and carefully plugged. Water in the small vials was to reserve for the isotopic measurement, $\delta^{18} \mathrm{O}$ (and $\delta^{2} \mathrm{H}$, not shown in this work), whereas the half-liter bottles were to conserve in the refrigerator for later chemical analysis. The electrical conductivity, EC, and the $\mathrm{pH}$ readings were immediately obtained by Hanna ${ }^{\mathrm{TM}}$ Instruments double-electrode, whose reading was to automatically correct to $25^{\circ} \mathrm{C}$. The chloride ion concentrations were to measure using Hanna $^{\mathrm{TM}}$ specific-ion electrode. The chemical analysis was to run at Cairo University.

The measurement of isotopic ratios, $\delta^{18} 0$ and $\delta^{2} \mathrm{H}$, were to run using laser quenching machines (ABB LGR-ICOS Los Gatos Research tunable diode laser analyzer, known as the Off-Axis Integrated Cavity Output Spectroscopy, OA-ICOS device, at the Radio-Analyses et Environnement, LRAE, École Nationale d'Ingénieurs, ENIS), Sfax, Tunisia, in duplicates. In parallel with the daily fresh Nile water sampling, a lab experiment was to run (in the period from to 18 April to 17 September 2017) to follow the changes in EC and the isotopic composition $\left(\delta^{18} \mathrm{O}\right.$ and $\left.\delta^{2} \mathrm{H}\right)$ of Nile water stock in evaporation pan, first in the lab, and then in class A pan in the field, at the Zankaloune Water Resources Research Station, about $100 \mathrm{Km}$ to the northeast of Cairo city, in Winter and Summertime 
of the year 2020. The hydrochemical and isotopic changes introduced to Nile water by the non-steadystate evaporation experiments can give a further interpretation of the results of the daily Nile water samples. The findings of the evaporation experiments are to be published elsewhere.

\section{Fundamental Formula for PULSE Waveform Model}

The PULSE waveform function (Equations 1A and B) was to develop on Excel ${ }^{\mathrm{TM}}$, where the built-in SOLVER macro was to run to obtain the values of model parameters via minimization of the sum of squares of deviation. The divergence is between the daily measured $\mathrm{EC}$ values and the calculated $\mathrm{f}(\mathrm{t})$ values as a function of time, both in $\mathrm{dS} / \mathrm{m}$ (or between the observed and predicted $\delta^{18} \mathrm{O} \%$ values vs. V-SMOW). The computed $\mathrm{f}(\mathrm{t})$ values were initially for the luminance, in the original optical formula, WEB 1, that we have initially adopted to develop our PULSE waveform function. Continuous posterior adjustments of the obtained values for model parameters were to manually carry out to get curve best fit as more $\mathrm{EC}$ values, $\mathrm{Cl}$ concentrations, and $\delta^{18} \mathrm{O}$ data-point ratios are to add to the spreadsheet progressively. The PULSE model periodic-waveform is to use to generate the frequency response useful in the interpretation of the time-dependent hydrochemistry and isotope hydrology data sets. The function has either three parameters $(\mathrm{L}, \mathrm{m}$, and $\mathrm{T})$ or five parameters when the optional parameter $\beta$ is to include, with its start factor $\gamma$ parameter, in the periodic time and frequency formula versions shown below

$$
\begin{array}{lll}
\mathrm{f}(\mathrm{t})= & \mathrm{L} *[1+(\mathrm{m}-(\mathrm{m} \beta / 100)) *(\sin (\theta /(\mathrm{T} * 0.985547362)))] \ldots \ldots \\
\mathrm{f}(\mathrm{t})= & \mathrm{L}+[\mathrm{L} *(\mathrm{~m}-(\mathrm{m} \beta / 100)) *(\sin (\theta *(f r *(1 / 0.985647362)))] .
\end{array}
$$

with

L Average of the PULSE. L value is constant for the time record. Its unit is as for $\mathrm{f}(\mathrm{t})$,

$\mathrm{m}$ Modulation ratio (called the contrast) $=($ the maximum minus the minimum $) /($ the maximum plus the minimum), $0<\mathrm{m}<1$, in response to the angular frequency, $\omega$, of the carrier input (but the ratio of direct current, dc, to alternating current, ac, components of the vision-test devices used in the electrophysiological experiments to run in optical medicine), dimensionless. The product $\mathrm{m} * \mathrm{~L}$ is the waveform amplitude that shows the climax position of the PULSE's peak above the average value, $\mathrm{L}$, in $\mathrm{dS} \mathrm{m}^{-1}, \mathrm{mg} \mathrm{l}^{-1}$ or $\delta^{18} \mathrm{O} \%$

$\mathrm{T}$ Periodic time $(\mathrm{T}=\theta / \omega=2 \pi / \omega)$, year

$t$ Time, day, expressed in angle $\theta$, rad, in our formula, but sec in the optical formula

$\theta$ The angle that expresses the concerned day $(\theta=\omega t)$ or $(2 \pi=\omega T)$, rad

$\omega$ Angular frequency $(\theta / t=2 \pi / T=2 \pi \mathrm{fr}) \mathrm{rad}^{-1}$, but rad $\mathrm{sec}^{-1}$ in the optical formula

fr Carrier frequency, $y^{-1}$, but $\mathrm{Hz}$ in the original optical formula

$\beta$ Damping factor; to change via the start factor, $\gamma$, downward the column used in the computation of $f(t)$ values in the spreadsheet, dimensionless

$\gamma$ Start factor to modify the optional parameter $\beta$ value, dimensionless

The main parameters are following

1- Modulation ratio, $\mathrm{m}=$ (maximum plus minimum $) /($ maximum minus minimum $), 0<\mathrm{m}<1$, dimensionless. This parameter controls the peak amplitude $\mathrm{mL}$ and the peak-to-trough amplitude $2 \mathrm{~mL}$ both to perceive on the $y$-axis.

2- Average L, $\mathrm{mg} / \mathrm{l}$, or $\mathrm{dS} / \mathrm{m}$, for ionic concentrations and $\mathrm{EC}$ values, respectively, or in per mil for isotopes, e.g., $\delta^{18} \mathrm{O}$. This parameter controls the vertical shift of the waveform.

3- Periodic Time, $\mathrm{T}=\theta / \omega=2 \pi / \omega$, year, with $\theta$ angle used to express the date, where $\theta=\omega t$, and $2 \pi=\omega \mathrm{T}$, rad, where $\omega$ is the angular frequency, $\omega=\theta / \mathrm{t}=2 \pi / \mathrm{T}=2 \pi f, \mathrm{rad}^{-1}$.

Changing the value of the periodic-time parameter, $\mathrm{T}$, year, will result in changing the carrier frequency, $1 / \mathrm{T}$, that expresses the number of the wave-pulses per year (to perceive on the $\mathrm{x}$-axis).

The $\mathrm{T}$ parameter controls the horizontal locus of the waveform pulses on a diagram showing the relationship between the concerned variable and date. 
The carrier frequency, $f r$, is related to the angular frequency $\omega$ (also called the carrier input) by the value of (double pi). The carrier frequency, $f r$, is to recognize for each calendar year on the $\mathrm{x}$-axis.

\section{Results and Discussion}

The recently collected data (late 2016 to early 2020) was to construct using daily records of measurements of EC in $\mathrm{dS} / \mathrm{m}, \mathrm{Cl}$ in ppm, and $\delta^{18} \mathrm{O} / \mathrm{V}-\mathrm{SMOW} \%$. The study will be further going on for one more year. Only EC data is to use in this work for waveform best fit. The introduced waveform function showed highly successful in hydrochemical data visualization. The values of model parameters are consistent with the information provided by the current river water-management that has taken place (by complete control of river flow downstream from Aswan, at the High-Dam) and flowing northward to Cairo and then to the Delta. However, the PULSE function is to further test for similar data to collect at Khartoum, Sudan, south of Lake Nasser, north of Aswan, and at the river mouths on the Mediterranean. Other hydrochemical variables are to plot via this waveform function to check for the applicability of this model for the visualization of conservative vs. non-conservative chemical variables. A personal record is to compare with historical monthly data sets for TDS in ppm to check the validity of the sampling interval (one sample per day). Significant improvement on the Nile waveform is to obtain when an automated optical device becomes available to get hourly EC measurements in the river course.

The PULSE waveform showed powerful when the data set is not fragmented, and when the sampling rate is adequate (i.e., daily vs. monthly). Interestingly, the comparison of recent data with the historical data revealed how much the River Nile south of Cairo has progressively become the ultimate trap of solutes from the cultivated lands in Upper Egypt during the last five decades as 150 to 250\% solute load increase is strikingly to observe.

Most of the increase in river-water solute load is due to leaching, baseflow, and dissolution, whereas the contribution of evaporation (despite its significance in the river water mass-balance) shows much less contribution to solute load increase in river water.

The later evidence was to obtain via the $\mathrm{EC}-\delta^{18} \mathrm{O}$ charts. Electrical conductivity is the easiest way to get an idea about the river solute load; however, EC is not conservative, while chloride is a conservative ion in river water. In contrast, the isotope ratio, $\delta^{18} \mathrm{O}$, is an excellent tracer of water provenance, mixing, and evaporation. Accordingly, the waveform is to test against the chronological data sets for the chloride ion concentrations shortly.

The critical finding for Nile EC data sets is the river water residence-time in the sizeable artificial lake Nasser reservoir in the south of Egypt. The waveform function has produced a periodic time of about 1.04 years, and the mass-balance of Lake Nasser is showing about a couple of years residence-time. The obtained $\mathrm{T}$ value for Cairo Nile affirms that the Lake reservoir can only ensure water supply downstream in Egypt for about one extra year if the inflow to the lake is to become absent. Such a limited hydro-margin reserve is too fragile. This point, once again, reflects the powerful tool this new waveform function is providing to the user. Hopefully, with this waveform, one may solve a complex issue like the residence time of water in a large river basin with simple means. Besides, the obtained periodic time, $\mathrm{T}$, of about one year for Cairo Nile water means a short transport time of the river water northward to the Capital.

Moreover, the rare event of a massive thunderstorm in Upper Egypt, late October 2016, was detected in the River Nile chemistry at Giza, and a small waveform was to construct for this anomalous event. Such a rare rainfall storm event revealed the isotopic composition, $\delta^{18} \mathrm{O}$, of the paleo-water masses that were to receive in the Nile basin in Egypt, in the early and middle Holocene, via comparison with the isotopic compositions of groundwater stored in the Wadi Natron aquifer to the southwest of the Nile Delta.

Besides, the daily ups and downs of the observed EC-values, above and below the waveform function fitted for Nile water during the work period (Oct 2016 - Apr 2018) is showing some micromass-fronts (small river water pulses) flowing northward from Upper Egypt Nile trunk to the Capital.

The current river regime, of the downstream River Nile basin in Egypt, as expressed by the applied PULSE waveform, is showing TDS trough, Fig. 1, in August, and two peaks in the transition 
of Winter 2016/17 and Winter 2017/18. The present-day river solute regime has progressively established during the last few decades, after the construction of the High Dam, $10 \mathrm{~km}$ to the south of Aswan city in the south of Egypt.

Comparison with TDS historical data, (not shown in this work), namely for the monthly-data of the years 1954, 1964, 1973, and 1979, Khalil and Fayez Saleeb Hanna, 1984) reveals that the ongoing regime has developed to the worse in terms of the river turned out to become a drain of its floodplain in Upper Egypt. During the historical floods, WEB 2 and WEB 3, that dominated the Nile flow in Egypt (before the cease of 1964 flood, and then the total flood halt by 1970), the lowest TDS values were appearing by the period of the annual flood peak, by late Summer time and early Autumn (i.e., in the three months of August-September-October). However, there were no strong TDS troughs in the two years 1954 and 1964.

Higher TDS values were prevailing in the river water during the rest of each year (called the "drought" stage) under the natural system (called the "old water regime") during the 9-month river low-stage, as contrary to the case during the 3-months of the annual flood season, Fig 2.

The year 1964 was unfortunate for the TDS-historical data record since it has seen the first "partial-closure" of the River Nile trunk (for the deviation of the river-course at a site about $10 \mathrm{~km}$ to the south of Aswan city, to allow the construction of High Dam in the river main channel). This "partial river closure" in the year 1964 had resulted in a temporary TDS increase at Cairo, within about one month, since the river flow was slow before the arrival, in the late months of that year, of the next flood (that was also partially stopped for allowing the progress of the High Dam construction.)

For the historical data of the two years 1973 and 1979, the TDS-trough turned out to appear earlier, during June and July (instead of August and September before the High Dam construction). This significant time shift in the appearance of the TDS-trough is due to the release of more water (from the water stock in Lake Nasser). This massive water release downstream in Spring and Summertime is to comply with the high Spring and Summer cultivation water-demand (corresponding to the "third crop" policy, that started to apply in the country shortly after the completion of the High Dam construction to fulfill the food demand in Egypt.)

\section{Conclusion}

The introduction of an easy to use waveform formula was needed to freely visualize the frequent temporal changes in river water chemistry and its isotopic composition without the limitations imposed on the oversimplified or extra-complex sinusoidal functions. In this respect, the three- to fiveparameter PULSE model, once installed in a spreadsheet, reveals the principal behavior of any river system. The involved calculations, however, impose the substitution of the 365.24218 days of the calendar year by 360 degrees sexagesimal. As well, the introduced formula can be used for the characterization of rare precipitation events, and even for predicting hidden paleo-groundwater recharge events in the river floodplain when archive $\delta^{18} \mathrm{O}$ data is available. Nonetheless, the full application of such a new formula further needs more verification of its utility in following-up the nonconservative solutes vs. the conservative solutes and other isotopes in stream water. Daily sampling is to recommend for getting a good outcome of such a waveform formula. The best achievement, however, will be the result of using automated EC measurements on the hourly time scale, using adequate optical devices. A copy of the Excel $^{\circledR}$ workspace is to obtain from the author upon request. 


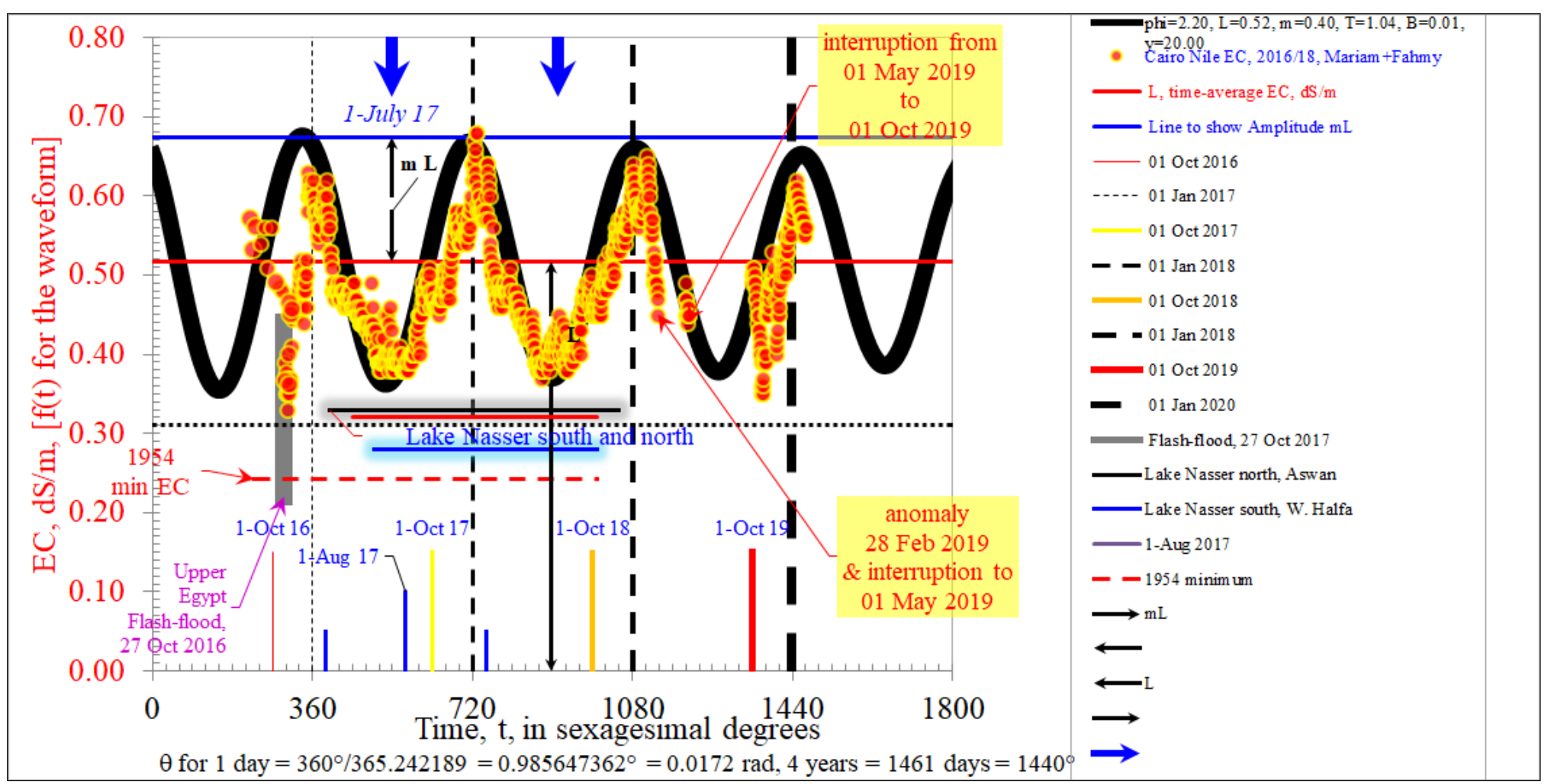

Figure 1 Waveform for EC, d/S/m, value for Nile water, Cairo, Egypt. The obtained waveform was to improve via introducing more measurements over four years.

$\mathrm{f}(\mathrm{t})=\mathrm{L} *[1+(\mathrm{m}-(\mathrm{m} \beta / 100)) *(\sin (\theta /(\mathrm{T} * 0.985547362)))]$

$\mathrm{f}(\mathrm{t})=0.5172 *[1+(0,40-(0.40 * 0.01 / 100)) *(\sin (\theta /(1.0416 * 0.985547362)))]$ 

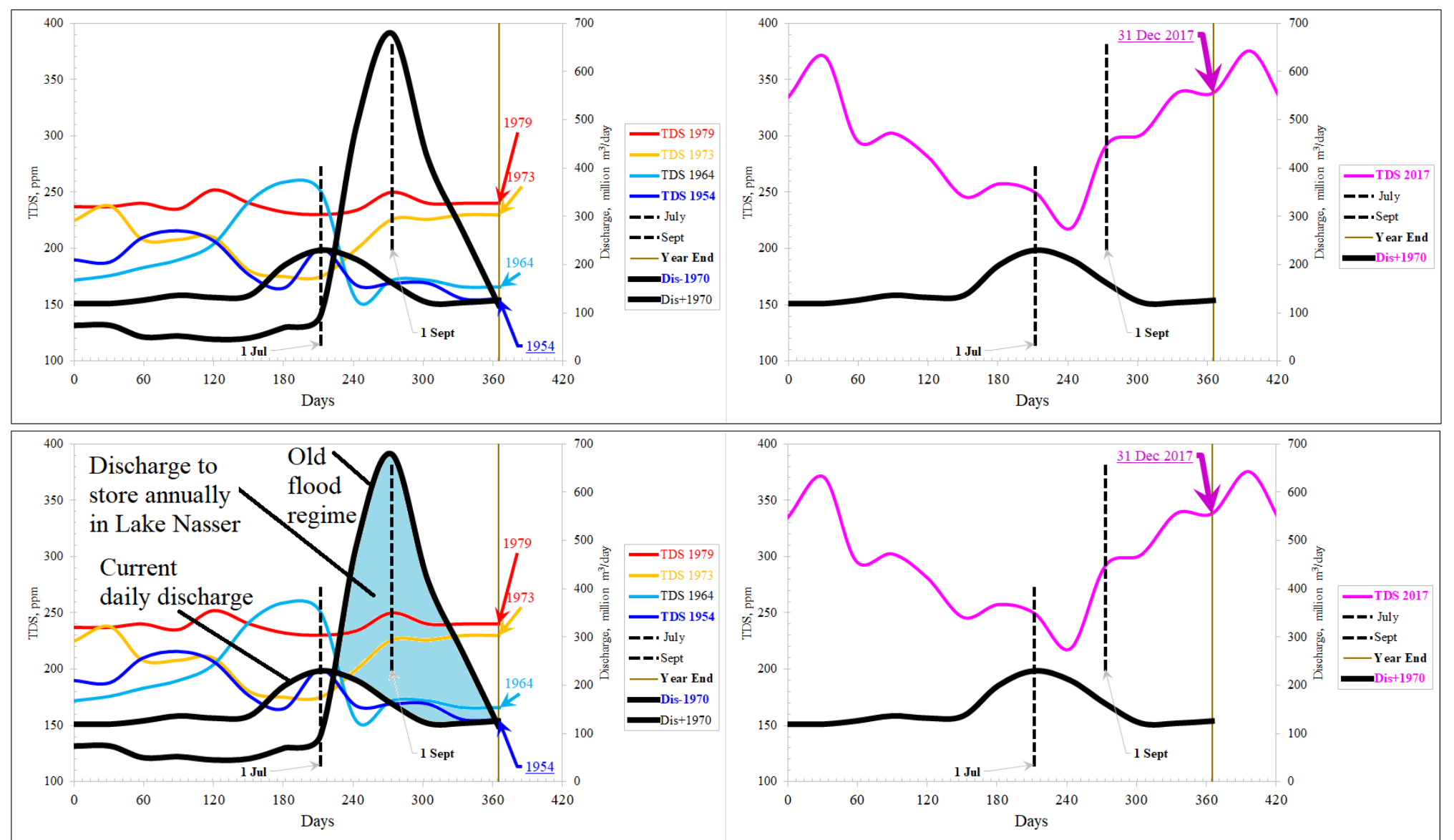

Figure 2 Diagrams showing the old (left) and the current (right) NILE discharge and TDS values at Cairo.

\section{Acknowledgment}

We thank Miss Mariam Nosser for Nile water sampling and lab measurements, at Cairo University, Egypt. Special thanks are friendly extended to the Sfax University Isotope Laboratory Staff Members, Tunisia, for good interest in carrying out the ${ }^{18} \mathrm{O}$ and ${ }^{2} \mathrm{H}$ isotope measurements.

\section{Conflict of interest}

We have no conflict of interest to declare.

\section{References}

Khalil J B and Fayez. Saleeb Hanna, 1984. Changes in the Quality of Nile Water in Egypt During the Twenty-Five Years, 1954-1979. Irrig Sci (1984) 5:1-13. Springer-Verlag.

WEB 1

https://books.google.com.eg/books?id=JCf7CAAAQBAJ\&pg=PA276\&lpg=PA276\&dq=can + we $+g$ enerate+non-

negative + values + by + sin? \& source $=$ bl\&ots $=$ MLJZdY2hd1\&sig $=$ wndPc8AKRSIi1rN8Ktf9y8WxOQ8\&

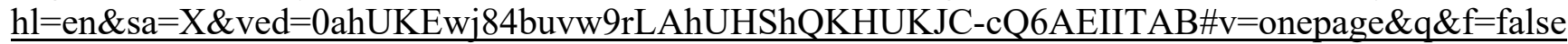

WEB 2

http://www.geotimes.org/apr05/feature_NileFloods.html

WEB 3

https://www.scribd.com/document/251548900/Climate-Change-Nile-Floods-and-Riparia 